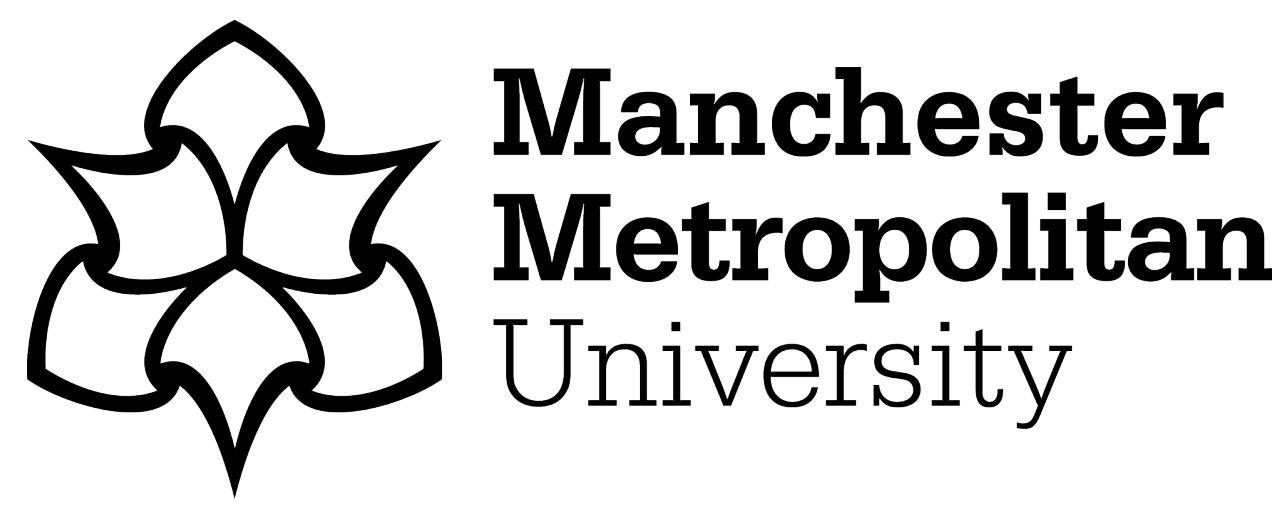

Masters, R, Capio, C, Poolton, J and Uiga, L ORCID logoORCID: https://orcid.org/0000-0002-5371-9428 (2018) Perceptual Modification of the Built Environment to Influence Behavior Associated with Physical Activity: Quasi-Experimental Field Studies of a Stair Banister Illusion. Sports Medicine, 48 (6). pp. 1505-1511. ISSN 0112-1642

Downloaded from: https://e-space.mmu.ac.uk/626981/

Version: Accepted Version

Publisher: Springer Verlag

DOI: https://doi.org/10.1007/s40279-018-0869-5

Please cite the published version 


\title{
Perceptual modification of the built environment to influence behaviour associated with physical activity: Quasi-experimental field studies of a stair banister illusion.
}

\begin{abstract}
Rich Masters ${ }^{1 \& 2 *}$, Catherine Capio ${ }^{1 \& 2}$, Jamie Poolton $^{2 \& 3}, \&$ Liis Uiga $^{1 \& 2}$
\end{abstract}
1 Te Huataki Waiora Faculty of Health, Sport and Human Performance, University of Waikato, New Zealand

${ }^{2}$ School of Public Health, Li Ka Shing Faculty of Medicine, The University of Hong Kong, Hong Kong

3 Carnegie School of Sport, Leeds Beckett University, United Kingdom

* Corresponding author [email: rich.masters@waikato.ac.nz]

Running head: Modifying the built environment to influence behaviour 


\begin{abstract}
Background. Re-engineering the built environment to influence behaviours associated with physical activity potentially provides an opportunity to promote healthier lifestyles at a population level. Here we present evidence from two quasiexperimental field studies in which we tested a novel, yet deceptively simple, intervention designed to alter perception of, and walking behaviour associated with, stairs in an urban area. Objectives. To examine whether stair banister adjustment has an influence on perceptions of stair steepness or on walking behaviour when approaching the stairs. Methods. In Study 1, we asked participants (n=143) to visually estimate the steepness of a set of stairs viewed from the top, when the stair banister was adjusted so that it converged with or diverged from the stairs $\left( \pm 1.91^{\circ}\right)$ or remained neutral $\left( \pm 0^{\circ}\right)$. In Study 2, the walking behaviour of participants $(n=36)$ was filmed as they approached the stairs to descend, unaware that the banister converged, diverged or was neutral. Results. In Study 1, participants estimated the stairs to be steeper if the banister diverged from rather than converged with the stairs. The effect was greater when participants were unaware of the adjustment. In Study 2, walking speed was significantly slower when the banister diverged from rather than converged with the stairs. Conclusions. These findings encourage us to speculate about the potential to economically re-engineer features of the built environment in order to provide opportunities for action (affordances) that invite physical activity behavior or even promote safer navigation of the environment.
\end{abstract}




\section{Key points.}

Visual perception of the steepness of a staircase was scaled by an easily engineered modification of the stair banister and, as a consequence, walking behaviour was influenced.

Further work is needed to examine the implication that design modifications to scale perception of the everyday built environment can be used to invite positive physical activity choices or safer navigation of the environment.

\section{Introduction}

A recent Topical Collection published in Sports Medicine (2016, Vol. 46) explored "how societies can move beyond the mere provision of information on health benefits of physical activity and exercise towards a more detailed understanding of how to design everyday environments that promote and invite physical activity" (p. 926) [1].

Activities, such as walking and stair climbing, are a function of the 'walkability' of the environment [e.g., 2, 3, 4]; however, re-engineering the existing built environment to promote walking or stair climbing is no easy task. Inspired by the ecological dynamics approach underpinning the Topical Collection, we conceived a novel design solution that potentially alters perception of the opportunities for action (affordances) [5] provided by stairs. In doing so, we sought to provide insight into whether it is feasible to nudge interpersonal interactions with the environment towards health- 
enhancing behaviours. We tested whether our novel solution, an unassuming, easily engineered, modification of a stair banister, changes visual perception of the steepness of the stairs (Study 1) and walking behaviour associated with using the stairs (Study 2).

The ecological framework [5] of the Topical Collection, and these studies, proposes that perception (of affordances) and action are highly integrated or coupled. Actions are regulated by information that emerges directly from the interaction between a person and the environment [e.g., 6,7,8,9]. Warren [9] famously demonstrated this by varying the riser height of stairs and asking people to judge whether the stairs were climbable. Judgments were a function not of riser height or of leg length, but of intrinsic metrics, the ratio between riser height and leg length.

The tight coupling between perception and action is also evident in demonstrations that perceptual judgments of the environment are scaled by the action capabilities of a person $[10,11]$. Fatigue, extra weight, hunger, low fitness, poor health or age, even fear, have all been shown to scale visual perception so that estimations of the steepness of hills or stairs is exaggerated [e.g., 12,13,14]. Taylor-Covill and Eves [15], for example, demonstrated that people with a greater desire for high-energy (rapid release) snacks (indicative of inadequate energy resources) visually overestimated the steepness of a set of stairs in a train station more than people who did not. Overestimating the steepness of stairs (or hills) facilitates avoidance of activities, such as (stair) climbing, that may exceed available energy resources or cause unnecessary physical risk [10]. ${ }^{1}$ However, an important consequence of avoiding stairs (or hills) is that we sacrifice the potential health benefits that accrue from physical activity associated with climbing them [e.g., 18].

\footnotetext{
${ }^{1}$ For related arguments, see Evolved Navigation Theory [16] and Error Management Theory [17].
} 
The ecological framework provides a platform for modifying how people perceive, and interact with, the built environment. It is clear that the spatial layout of the environment can create illusory effects on perception [19], but no study of which we are aware has examined whether stair perception can be scaled by simple modification of commonplace mechanical constraints associated with the stair environment (e.g., the stair banister). We therefore asked in Study 1 whether altering the angle of the banister (handrail) on a staircase, creates a distortion of linear perspective that increases or decreases the perceived geometric slant of the stairs. We obtained estimations of the steepness of a staircase at a city sports center on separate occasions when the banister converged with or diverged from the stairs, or was normal. Estimations were obtained using a visual-matching method [e.g., 12,13], first when participants were unaware of the intervention and then when they were aware of the intervention. Conscious awareness is a corollary of the way in which visual information is processed by the human perception-action system. For example, the prominent two visual systems hypothesis proposes that vision for perception and vision for action occur in separate neuroanatomical pathways of the brain, the ventral stream and the dorsal stream, respectively $[20,21]$. Vision for perception generates a detailed representation of the environment, which is necessary for recognition and identification of size, shape, slope and so on, and of which the perceiver is consciously aware. Vision for action, on the other hand, generates rapid, nonconscious visual processing of information that guides movements. Consequently, we were interested not only in whether participants would be aware of the relatively small changes in banister angle that we introduced $\left( \pm 1.91^{\circ}\right)$, but also in whether awareness would moderate estimations of the slant of the stairs. 
We expected that lowering the banister at the bottom of the stairs would cause the parallel lines of the stairs and banister to converge when viewed from the top, which would make the stairs appear to be shallower than they were. We expected that raising the banister at the bottom of the stairs would cause the lines to diverge when viewed from the top, which would make the stairs appear to be steeper than they were.

\section{Study 1}

\subsection{Methods}

2.1.1 Design and Sample. In a quasi-experimental field study authorized by the university ethics committee, 143 passersby who approached a set of stairs at a local sports center were invited to estimate the slant of the stairs after providing informed consent and before descending. The banister (as viewed from the top) either converged with or diverged from the stairs, or remained neutral $(\mathrm{n}$ converged $=49, \mathrm{n}$ diverged $=42, \mathrm{n}_{\text {neutral }}=52 ; 32$ female, 111 male; aged 15 to 58 years, mean age $23.01 \pm$ $7.35)^{2}$

2.1.2 Measures. The estimation task (visual-matching) required participants to rotate a plastic disk until a line on the disk subtended the horizontal plane at an angle that matched what they believed to be the exact slant of the stairs (see Figure 1). A protractor was attached to the back of the disk so that the experimenter could record the estimated angle. No feedback regarding estimation accuracy was provided.

Figure 1 here

\footnotetext{
2 Order of banister adjustment was not counterbalanced, but there is no reason to believe that the day of the week upon which adjustments occurred (Tuesday, Wednesday, Thursday) influenced sampling or responses. Participants who had completed an estimate on a previous day were not tested.
} 
2.1.3 Intervention. We adjusted a single rail stair banister (black metal) attached securely to the left side of a staircase that was $219 \mathrm{~cm}$ wide (12 stairs; decline $26.5^{\circ}$; riser height $140 \mathrm{~mm}$; tread depth $300 \mathrm{~mm}$ ). The banister was $300 \mathrm{~cm}$ in length and ended at the second bottom step. When positioned conventionally (neutral), the banister was elevated $100 \mathrm{~cm}$ above the stairs and anchored by a leg at the top and the bottom of the staircase. The gradual elevation of the banister was increased or decreased by $10 \%\left( \pm 1.91^{\circ}\right)$ by lengthening or shortening the leg at the bottom of the staircase.

2.1.4 Procedure. Participants were asked to make two estimations of the downward slant of the stairs (see 2.1.2) when standing two paces back from the leading edge of the top step. For both estimations, they were instructed to "rotate the disk until the line represents your exact view of the steepness of the stairs". After the first estimation (unaware condition), a manipulation check was conducted to determine whether participants were aware of the banister adjustment. They faced away from the staircase and were asked to "indicate which of the eight side-elevations [presented on an A4 sheet of white paper] most accurately represents the existing relationship between the stairs and the banister" (see Figure 2). The banister converged (-5\%, $10 \%,-15 \%)$ or diverged $(+20 \%,+15 \%,+10 \%,+5 \%)$ in each side-elevation or was neutral $(0 \%)$. Following the manipulation check, participants were informed that the aim of the study was to examine the role of stair banister angle on visual perception of stairs (they were not informed of which banister condition they were in). A second estimation was then completed (aware condition). ${ }^{3}$

\footnotetext{
${ }^{3}$ In order to avoid drawing the attention of participants to the banister-stairs relationship, participants had to complete the unaware condition first, so it was not possible to counterbalance aware/unaware conditions.
} 
Figure 2 here

\section{Results}

3.1 Manipulation check. Participants in the converging, diverging and neutral banister conditions identified side-elevations with mean banister elevation of $-1.84 \pm 1.37 \%$, $1.07 \pm 1.54 \%$ and $-0.29 \pm 1.51 \%$, respectively. One-way analysis of variance, controlling for age and sex, ${ }^{4}$ revealed that the means were not significantly different, $p=0.787$, and one sample t-tests showed that they did not differ significantly from $0 \%$ elevation (neutral), all $p$ 's $>0.05$. The findings from the manipulation check show that on average participants identified the side-elevation that represented a neutral (parallel) relationship between the banister and stairs. This implies that during the first estimation, participants in the converging and diverging banister conditions were unaware of the adjustment.

\subsection{Visual-matching estimations. Two-way analysis of covariance (banister $\mathrm{x}$} awareness) with repeated measures on the latter condition, controlling for age and sex (see Footnote 4), showed that although estimations appeared to be more accurate when participants were aware that the banister had been modified (see Figure 3), the effect was not significant, $p=0.893$. An interaction between banister condition and awareness was not evident, $p=0.530$; however, there was a main effect of banister condition, $F_{2,138}=4.013, p=0.020, \eta_{\mathrm{p}}{ }^{2}=0.055$. Bonferroni adjusted follow-up tests revealed that estimations were greater when the banister diverged from the stairs compared to when the banister converged with the stairs, $p=0.017$, regardless of whether participants were aware or unaware of the banister manipulation. No other differences were evident, $p$ 's $>0.05$.

\footnotetext{
${ }^{4}$ Both age and sex have been shown to influence perceptions of stairs/hills [e.g.,12,13,15,18].
} 
One sample t-tests, using the actual angle of the stairs $\left(26.5^{\circ}\right)$ as the test value, showed that the angle of the stairs was overestimated in all banister conditions, $p$ 's $<$ 0.001

Figure 3 here

\section{Discussion}

Consistent with our expectations, when participants visually estimated the slant of the stairs from the top they perceived them to be significantly steeper if the banister diverged from rather than converged with the stairs. The effect remained when participants were informed of our interest in the role of stair banister angle on perception of stair steepness.

An important question, however, is whether there is an effect of banister adjustment not only on perception of the stairs but also on behaviours associated with use of the stairs. From an ecological dynamics perspective, using an illusion to alter perceived opportunities for action afforded by the stairs may influence actions on the stairs; however, the two-visual systems hypothesis [20,21] suggests that vision for perception not vision for action is affected by illusions [22]. Nevertheless, there is evidence that seems to suggest visual illusions not only modify perception of the stimulus that is acted upon, but also cause positive changes in actions associated with that stimulus $[23,24,25,26,27]$. In golf, for instance, participants who perceived a golf hole as larger when it was surrounded with small circles as opposed to large circles (the Ebbinghaus illusion) also putted more accurately to the hole [23,25,26,27].

Consequently, having shown that adjusting the angle of a banister influences perceptions of the stairs environment (i.e., slant), we asked in Study 2 whether this 
has an influence on walking behaviour.

\section{Study 2}

\subsection{Method}

In a second field study authorized by the university ethics committee and for which informed consent was obtained from all participants, 36 students studying for a degree in exercise and health descended the same stairs as in Study 1 on three different occasions on the same day. The students were informed that they were taking part in a study of decision-making in sport (a cover story). Two Casio EX-FH100 64 Hz digital cameras were hidden beside the staircase to surreptitiously record the walking behavior (mean step length, final step length prior to descent, speed) of participants during the final three steps before descending the stairs. Kinovea video analysis freeware was used to calculate the distance between toe-off for one foot to toe-off for the other foot (one step). Speed was calculated by the distance covered during the three steps divided by time. Video data for 3 participants was lost due to equipment malfunction, so analysis of the walking behavior of participants included 10 females and 23 males (mean age 19.79 \pm 0.89 years; age range 18-21 years; mean height $170.99 \pm 7.61 \mathrm{~cm})$. After participants descended the stairs to participate in the decisionmaking study, they returned to the top of the stairs via a shallow path that detoured away from the staircase $(\sim 200 \mathrm{~m})$. During each descent $(\mathrm{N}=3)$, the banister either converged with or diverged from the stairs by $10 \%\left( \pm 1.91^{\circ}\right)$, or remained neutral ( $\pm 0 \%$ ), as in Study 1. Order of banister condition was counterbalanced and the banister was adjusted without participants' knowledge. ${ }^{5}$

\footnotetext{
${ }^{5}$ During debriefing, no student indicated awareness that the banister had been adjusted.
} 
As a manipulation check, participants were asked to estimate the slant of the stairs (idem Study 1) at the end of the study. Estimations were therefore based upon the final (counterbalanced) banister condition in which they participated.

\section{Results}

6.1 Manipulation check of visual-matching estimations. Mean estimation angles in the converging, diverging and neutral banister conditions were $30.81 \pm 8.75^{\circ}, 39.82 \pm 11.16^{\circ}$ and $39.20 \pm 11.08^{\circ}$, respectively. One-way analysis of variance, controlling for age and sex, revealed that the means were statistically different, $F_{2,32}=3.947, p=0.031, \eta \mathrm{p}^{2}=$ $0.226 .{ }^{6}$ Consistent with Study 1, Bonferroni adjusted follow-up tests showed that participants who viewed the stairs when the banister diverged displayed significantly higher estimations of slant than participants who viewed the stairs when the banister converged, $p<0.033$. No other differences were evident, $p$ 's $>0.05$. Again, one sample t-tests showed that the angle of the stairs $\left(26.5^{\circ}\right)$ was overestimated in all banister conditions, $p$ 's $<0.05$ (one-tailed).

6.2 Walking speed. Mean walking speeds during the three steps prior to descending the stairs in the converging, diverging and neutral banister conditions were $1.38 \pm 0.19$ $\mathrm{m} / \mathrm{s}, 1.23 \pm 0.24 \mathrm{~m} / \mathrm{s}$ and $1.35 \pm 0.22 \mathrm{~m} / \mathrm{s}$, respectively. One-way analysis of variance with repeated measures revealed that the walking speeds differed significantly, $F_{2,64}=$ 4.490, $p=0.015, \eta p^{2}=0.123$. Bonferroni adjusted follow-up tests revealed that mean walking speed was slower when the banister diverged than when it converged, $p=$ 0.012. No other differences were evident, $p$ 's $>0.05$.

\subsection{Mean step length and mean final step length prior to descent. Mean step length} during the three steps prior to descending the stairs in the converging, diverging and

\footnotetext{
${ }^{6}$ Estimation data for one participant was unavailable, so the sample therefore included 10 females and 22 males.
} 
neutral banister conditions were $0.65 \pm 0.08 \mathrm{~m}, 0.66 \pm 0.08 \mathrm{~m}$ and $0.63 \pm 0.09 \mathrm{~m}$, respectively. No differences were evident between the banister conditions $(p>0.05)$. Mean final step length prior to descending the stairs in the converging, diverging and neutral banister conditions were $0.60 \pm 0.15 \mathrm{~m}, 0.60 \pm 0.14 \mathrm{~m}$ and $0.57 \pm 0.16$, respectively. No differences were evident between the banister conditions $(p>0.05)$.

\section{General Discussion}

When viewed from the top, stairs upon which the banister diverged were perceived as steeper compared to stairs upon which the banister converged (Study $1 \& 2$ ). Misalignment of the banister (a single rail) may have distorted perception of the geometric slope of the staircase by creating converging or diverging lines of perspective [28], as in geometrical-optical illusions like the Poggendorff, Hering, Ponzo and Zöllner illusions [e.g., 29, 30].

Eves et al. [18] described stairs as man-made hills that represent relatively steep slopes in the built environment $\left(\sim 20^{\circ}\right.$ to $\left.30^{\circ}\right)$ and suggested that overestimation of their steepness acts as a cue to pedestrians to use less energy demanding forms of transportation (e.g., escalators/lifts) that are available at the point of choice. In our studies, participants had no option to use an escalator or lift, so further studies are needed to test whether adjustment of the banister influences point of choice decisions. It is possible that a banister that converges towards the bottom of the stairs, and thus diverges towards the top, will moderate overestimations of stair steepness by pedestrians approaching from the bottom. Presumably, stairs that appear less steep are perceived as less energy demanding forms of transportation, which might shift point of choice decisions away from escalators or lifts. That is, re-engineering staircases may lead to the emergence of positive physical activity behaviors. 
Participants walked more slowly if they approached the stairs when the banister diverged rather than converged (Study 2), suggesting that perceptions of steepness moderated walking speed. This finding is consistent with the suggestion that people walk more slowly during the final two anticipatory strides preceding transition to stair descent if they are concerned about the apparent steepness of the stairs [31]. Altered behavior by a person approaching the stairs does not necessarily imply that actions on the stairs will also be influenced by the illusion. The planning-control model of perception and action [32] argues that illusions influence the planning of actions but not online control of the actions; errors caused by the illusion can therefore be corrected as the action unfolds. Consequently, it is possible that the diverging banister influenced approach behavior but not stepping behavior.

Other empirical work provides a reason to believe that the bannister illusion may influence action on the stairs. Vertical black and white bars superimposed on the riser of a single step not only caused participants to overestimate the height of the step, but also to significantly increase toe elevation when mounting the step [33, see also 34]. We find this particularly thought provoking when considering that people who are concerned about falling [35], or who have movement disorders [e.g., 36,37], generally demonstrate a greater propensity to consciously control their movements [see the theory of reinvestment, 38]. Gonzalez et al. [39] demonstrated that high conscious movements are more susceptible to modification by illusions than low conscious movements. ${ }^{7}$ Consequently, stepping parameters of people afraid of falling (often older adults), or of people with movement problems, even those who are overweight, may be more easily influenced by the banister illusion.

\footnotetext{
${ }^{7}$ Participants indicated the size of the aperture created by a Ponzo illusion with the thumb and index finger (automated, low conscious) or with the thumb and ring finger (awkward, high conscious).
} 
Stepping parameters, such as, minimal clearance between the foot and stair edge, are implicated in falls on stairs [e.g., 40,41], but unfortunately our covert filming of participants' stair descent did not allow reliable analysis of stepping parameters. Further work is therefore needed to test whether the banister illusion positively (or negatively) moderates stepping parameters during descent (or ascent) of stairs.

Taken together, the findings from Study 1 and Study 2 suggest that subtly adjusting cues in the built environment has potential to moderate (or exacerbate) perceptions of geometric slant, which then influences walking behaviour. We therefore believe that our novel design solution has potential to alter the opportunities for action (affordances) [5] provided by stairs, and thus to nudge interactions with the environment towards health-enhancing behaviours [1].

Further work needs to examine the impact of the banister illusion in different populations and community groups, including older adults, children, overweight people and those who have movement problems. Such knowledge may be invaluable for planners of retirement communities or children's playgrounds, for example, who need to design everyday environments that both promote physical safety and invite physical activity - all in a cost-efficient way.

\section{Compliance with Ethical Standards}

Ethical approval: All procedures were in accordance with the ethical standards of the institutional research committee and with the 1964 Helsinki declaration and its later amendments.

Funding: No sources of funding were used to assist preparation of the manuscript. Conflict of interest: Rich Masters, Catherine Capio, Jamie Poolton and Liis Uiga have no conflicts of interest associated with the manuscript. 


\section{References}

[1] Brymer E, Davids K. Designing environments to enhance physical and psychological benefits of physical activity: A multidisciplinary perspective. Sports Med. 2016;46:925-6.

[2] Frank LD, Sallis JF, Saelens BE, et al. The development of a walkability index: Application to the Neighborhood Quality of Life Study. Br J Sports Med. 2010;44:924-33.

[3] Giles-Corti B, Vernez Moudon A, Reis R, et al. City planning and population health: A global challenge. Lancet. 2016;388:2912-24.

[4] Moura F, Cambra P, Goncalves AB. Measuring walkability for distinct pedestrian groups with a participatory assessment method: A case study in Lisbon. Landsc Urban Plan. 2017;157:282-96.

[5] Gibson JJ. The ecological approach to visual perception. Hillsdale: Erlbaum; 1979.

[6] Adolph KE, Eppler MA, Gibson EJ. Crawling versus walking infants' perception of affordances for locomotion over sloping surfaces. Child Dev. 1993;64:1158-74.

[7] Fajen BR. The scaling of information to action in visually guided braking. J Exp Psychol Hum Percept Perform. 2005:31:1107-23.

[8] Lee DN, Lishman R. Visual control of locomotion. Scand J Psychol. 1977; 18:224-30.

[9] Warren WH. Perceiving affordances: Visual guidance of stair climbing. J Exp Psychol Hum Percept Perform. 1984;10:683-703.

[10] Proffitt DR. Embodied perception and the economy of action. Perspect Psychol Sci. 2006;1:110-22.

[11] Witt JK, Linkenauger S, Wickens C. Action-specific effects in perception and 
their potential applications. J Appl Res Mem Cogn 2016:5:69-76.

[12] Bhalla M, Proffitt DR. Visual-motor recalibration in geographical slant perception. J Exp Psychol Hum Percept Perform. 1999;25:1076-96.

[13] Proffitt DR, Bhalla M, Gossweiler R, et al. Perceiving geographical slant. Psychon Bull Rev. 1995;2:409-28.

[14] Stefanucci JK, Proffitt DR, Clore G, Parekh N. Skating down a steeper slope: Fear influences the perception of geographical slant. Percept. 2008;37:321-3.

[15] Taylor-Covill GAH, Eves FF. When what we need influences what we see:

Choice of energetic replenishment is linked with perceived steepness. J Exp Psychol Hum Percept Perform. 2014;40:915-9.

[16] Jackson RE, Cormack LK. Evolved navigation theory and the descent illusion. Percept Psychophys. 2007;69:353-62.

[17] Haselton MG, Buss DM. Error management theory: A new perspective on biases in cross-sex mind reading. J Pers Soc Psychol. 2000;78:81-91.

[18] Eves FF, Thorpe KS, Lewis A, et al. Does perceived steepness deter stair climbing when an alternative is available? Psychon Bull Rev. 2014;21:637-44.

[19] Coren S, Girgus J. Seeing is deceiving: The psychology of visual illusions. Hillsdale: Erlbaum; 1978.

[20] Goodale M, Milner AD. Separate visual pathways for perception and action. Trends Neurosci. 1992;15:20-5.

[21] Milner AD, Goodale M. Two visual systems re-viewed. Neuropsychol. 2008;46:774-785

[22] Aglioti S, DeSouza JFX, Goodale M. Size-contrast illusions deceive the eye but not the hand. Curr Biol 1995;5:679-85.

[23] Chauvel G, Wulf G, Maquestiaux F. Visual illusions can facilitate sport skill 
learning. Psychon Bull Rev. 2015;22:717-21.

[24] Denton GG. The influence of visual pattern on perceived speed. Percept. $1980 ; 9: 393-402$

[25] Gray R. Being selective at the plate: Processing dependence between perceptual variables relates to hitting goals and performance. J Exp Psychol Hum Percept Perform. 2013;39:1124-42.

[26] Witt JK, Linkenauger SA, Proffitt DR. Get me out of this slump! Visual illusions improve sports performance. Psychol Sci. 2012;23:397-9.

[27] Wood G, Vine S, Wilson M. The impact of visual illusions on perception, action planning, and motor performance. Atten Percept Psychophys. 2013;75:830-4.

[28] Gregory RL. Distortion of visual space as inappropriate constancy scaling. Nature. 1963;199:678-80.

[29] Weintraub DJ, Krantz DH, Olson TP. The Poggendorff illusion: Consider all the angles. J Exp Psychol Hum Percept Perform. 1980;6:718-25.

[30] Westheimer G. Illusions in the spatial sense of the eye: Geometrical-optical illusions and the neural representation of space. Vision Res. 2008;48:2128-42. [31] Peng J, Fey NP, Kuiken TA, et al. Anticipatory kinematics and muscle activity preceding transitions from level-ground walking to stair ascent and descent. J Biomech. 2016;49:528-36. [32] Glover SR, Dixon P. Dynamic illusion effects in a reaching task: Evidence for separate visual representations in the planning and control of reaching. J Exp Psychol Hum Percept Perform. 2001;27:560-72.

[33] Elliott DB, Vale A, Whitaker, D, et al. Does my step look big in this? A visual illusion leads to safer stepping behaviour. PLoS One. 2009;4:e4577. doi:10.1371/journal.pone.0004577. 
[34] Rhea CK, Rietdyk S, Haddad JM. Locomotor adaptation versus perceptual adaptation when stepping over an obstacle with a height illusion. PLoS One. 2010;5(7):e11544. doi:10.1371/journal.pone.0011544.

[35] Wong T, Masters RSW, Maxwell JP, Abernethy BA. Reinvestment and falls in community-dwelling older adults. Neurorehabil Neural Repair, 2008;22:410-4. [36] Masters RSW, Pall HS, MacMahon KMA, Eves FF. Duration of Parkinson disease is associated with an increased propensity for 'reinvestment'. Neurorehabil Neural Repair. 2007;21:123-6.

[37] Orrell A, Masters, RSW, Eves FF. Reinvestment and movement disruption following stroke. Neurorehabil Neural Repair. 2009;23:177-83.

[38] Masters RSW, Maxwell JP. The theory of reinvestment. Int Rev Sport Exerc Psychol. 2008;1:160-83.

[39] Gonzalez CLR, Ganel T, Whitwell RL, Morrissey B, Goodale MA. Practice makes perfect, but only with the right hand: Sensitivity to perceptual illusions with awkward grasps decreases with practice in the right but not the left hand.

Neuropsychol. 2008;46:624-31.

[40] Hamel KA, Okita N, Higginson JS, et al. Foot clearance during stair descent: effects of age and illumination. Gait Posture. 2005;21:135-40.

[41] Zietz D, Johannsen L, Hollands M. Stepping characteristics and centre of mass control during stair descent: Effects of age, fall risk and visual factors. Gait Posture. 2011;34:279-84. 


\section{Figure legends}

Figure 1. Apparatus used by participant to estimate the slant of the stairs (visualmatching).

Figure 2. Participants were asked to face away from the staircase and to indicate the image that most accurately represented the stairs and banister. Image order was randomized (this panel: $\mathrm{A},+10 \%$; $\mathrm{B},+5 \%$; C, $-15 \%$; D, $-5 \%$; E, $+20 \%$; F, 0\%; G, $10 \% ; \mathrm{H},+15 \%)$.

Figure 3. Mean and S.E. of visual-match estimations of slant angle, viewed from the top of the staircase when participants were aware or unaware that the banister diverged from or converged with the stairs by $10 \%$, or was unadjusted (neutral). Dashed line indicates actual slant of the staircase $\left(26.5^{\circ}\right)$. 


$$
\text { (1) }
$$



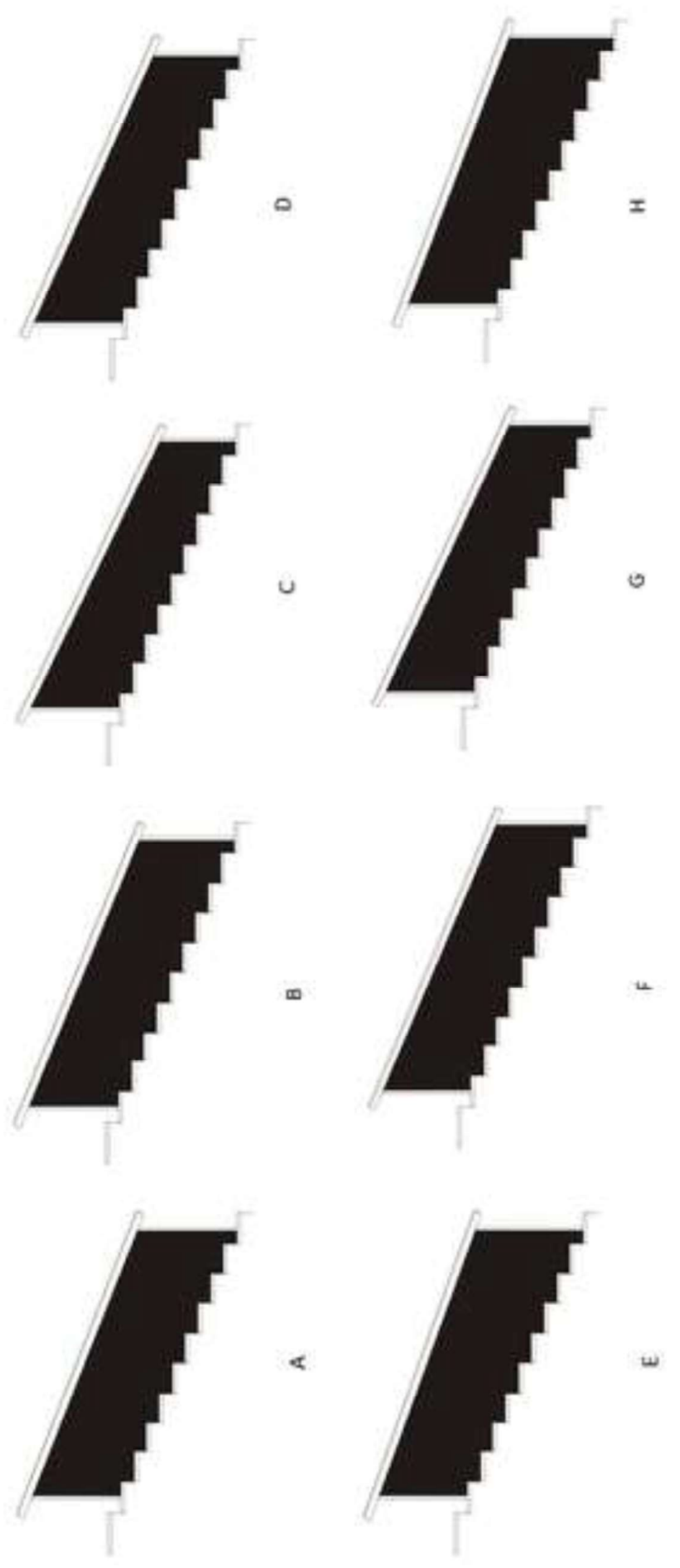

N
$\frac{0}{5}$
$\frac{\mathfrak{g}}{4}$ 

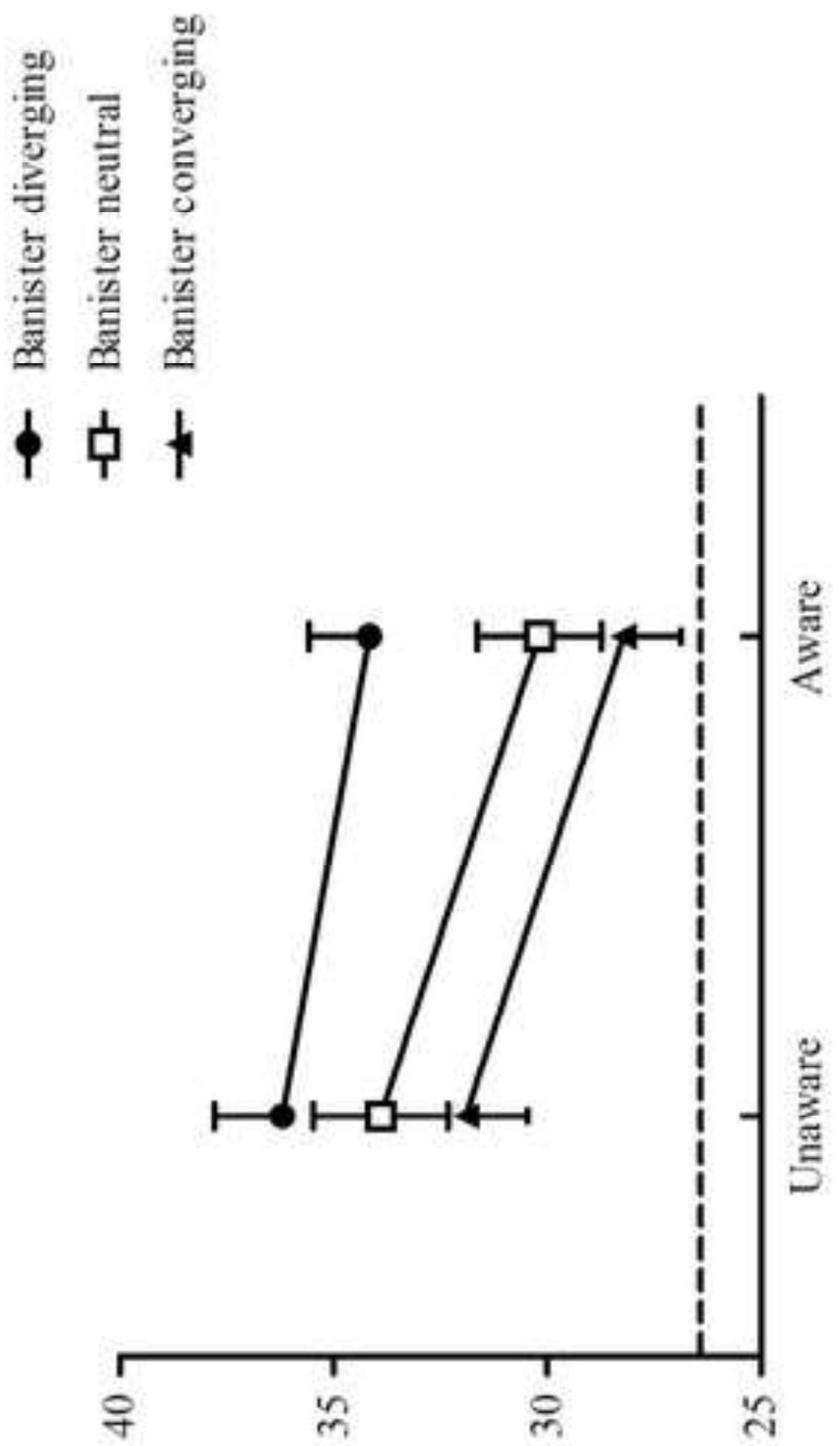

总

$m$
$\frac{m}{5}$
$\frac{9}{2}$ 